regular. She had had rheumatic fever seven years ago and a year before admission to hospital she was confined to bed for six weeks for what she described as catarrh of the stomach. After her recovery from this illness she complained of pain in the back and for the first time noticed a swelling on the right side of the abdomen. There was no history of jaundice. On examina. tion the patient was rather thin and nervous looking. Beyond some frequency of micturition the urinary and other systems were normal. On inspecting the abdomen, otherwise flat, a prominent swelling could be made out on the right side, its centre being slightly below the level of the umbilicus. It was tender, smooth, elastic, but not fluctuating. There was a distinct area of resonance between its upper border and the lower margin of the liver. The percussion note was dull over the tumour which was extremely moveable in all directions. On pushing it downwards its lower border reached almost to the level of the pubes. The aterus and appendages appeared to be normal. The abdomen was opened by a vertical incision over the most prominent part of the swelling. The right kidney was found to be normal and the tumour proved to be a distended gallbladder, retort shaped, and of about the size of a cocoanut. Into its upper part there ran a very thin flap of liver tissue, while its lower border was round and free from adhesions. On opening the tumour pale fluid escaped. The cystic duct was blocked by three faceted calculi. These were removed along with the greater part of the cyst wall, the remaining portion being sutured to the parietal wound and drained. A week after operation bile escaped from the wound which is now completely closed.

In this case the absence of a history of jaundice, accounted for by the cystic duct alone being obstructed, the area of resonance at the upper border of the tumour, along with the fornices being free of anything suggesting a pelvic origin, pointed to the condition being renal rather than connected with the gall-bladder or ovary.

Dundee.

\section{A METHOD OF STERILISING SPONGES.}

BY F. W. ANDREWES, M.D. OXON., F.R.C.P. LOND.,

PATHOLOGIST AND LECTURER ON PATHOLOGY, ST. BARTHOLOMEW'S HOSPITAL, ETC.

A YEAR or more ago I published, in conjunction with Dr. K. J. P. Orton, the results of a study of the disinfectant action of hypochlorous acid. ${ }^{1}$ In that paper we showed that -in the absence of easily oxidisable organic matter hypochlorous acid is one of the most intense germicides known, even anthrax spores being killed in one minute by a 0.01 per cent. solution. In the presence of much organic matter the pure acid is comparatively inert but we described a combination of ammonium persulphate with hydrochloric acid in which practical advantage may be taken of the high activity of hypochlorous acid as a disinfectant, even in presence of moderate amounts of organic matter. It is to this combination that $I$ wish to draw attention in connexion with the sterilisation of sponges.

The credit of first devising, for practical use in surgery, a bighly active combination of hydrochloric acid with an oxidising agent belongs to Krönig and Paul. ${ }^{2}$ The mixture which they recommended-a 1 per cent. solution of potassium permanganate to which 1 per cent. of strong $\mathrm{HCl}$ has been added-will kill anthrax spores in 30 seconds and is certainly a skin disinfectant of the highest efficiency. Its staining properties are, however, very inconvenient and it was in order to obviate this objection that Dr. Orton and I experimented with the persulphate of ammonium. This salt, $\left(\mathrm{NH}_{3}, \mathrm{~S}_{2} \mathrm{O}_{3}\right.$, forms a colourless solution in water and on adding to the solution strong hydrochloric acid the latter is oxidised but much more slowly than by the permanganate. The exact mixture which we advocated is made up as follows : 37 grammes of ammonium persulphate are dissolved in 950 cubic centimetres of pure distilled water and 11 cubic centimetres of strong hydrochloric acid are then added. When first made up the mixture has no very extraordinary germicidal powers, but in the course of a few days these become very pronounced and when six days old it will kill anthrax

1 Centralblatt fir Bakteriologie, vol. xxxv., pp. 645 and 811 2 Zeitschrift für Hygiene, vol, xxv., p. 73 . spores in less than one minute. It retains its efficiency for many weeks. It is a perfectly clear, colourless solution, with no staining powers and no injurious action on the skin, though it may fix blood stains in the crevices of the nails. It was as a skin disinfectant that we chiefly suggested its use, and I have successfully employed it as such for some time. Mr. W. Bruce Clarke, who tried it for a time in his surgical practice, had on one occasion some eczema of the hands after he had been operating for a whole afternoon, bat others have not had this experience.

But whether or not the persulphate mixture proves a suitable skin disinfectant I feel very sure after several trials that it is one of the best and speediest means for sterilising sponges which can be found. I have subjected it to tests far more severe than any which can occur in actual practice. I will describe one which I recently carried out. I obtained from the operating theatre an old sponge which had been discarded because it had become discoloured. It was taken to the post-mortem room and soaked in blood and fæces; in this state it was left all night. Next morning I poured over it a quantity of sewage which had been standing in a bottle in the laboratory for a fortnight and which was in a highly offensive condition. Finally $\mathbf{I}$ added an emulsion of hay bacillus spores, which are much more resistant than those of anthrax. I now cleansed the sponge mechanically under a hot water tap, scrubbing it two or three times in succession with soap. After five minutes it appeared clean. I squeezed it out once or twice in the persulphate mixture, which had been made up four days previously, and then placed it in a large beaker of the mixture so that it was completely covered. After an hour I cut off two large pieces and placed them in sterile broth, using, of course, sterilised instruments for the purpose. I changed the broth an hour or two later to make sure of getting rid of all traces of the disinfectant, though this was hardly needful, as the organic matter of the broth rapidly decomposes the hypo. chlorous acid. After four days' incubation at blood heat both tubes remained absolutely sterile. More than this, I left the sponge soaking in the persulphate mixture for four days and at the end of that period it came out beautifully bleached and looking like a new sponge. Nor were its texture and elasticity in any way impaired. This is only one out of several similar experiments which I have performed on sponges and it will be admitted that it can hardly have been exceeded in severity.

Some of the methods in common use for the preparation of sponges for surgical purposes occupy several days. By this method they can be sterilised with certainty in an hour, whereby considerable economy in the stock of sponges required can be effected. Moreover, discoloured sponges can be bleached and renovated. For this latter purpose a sojourn of two or three days in the mixture is requisite. For mere sterilisation an hour is ample; the sponges should then be rinsed in sterile water and stored in carbolic solution. This is advisable because the persulphate does exercise a certain injurious effect on their texture. I find that if they are kept soaking in the mixture for three or four weeks they become softened and eventually disintegrate, hence the shorter the sojourn at each sterilisation the longer will be the life of the sponge.

I would emphasise two facts in connexion with this method. First, the persulphate mixture should bave been made up at least four days before use but preferably not more than a month. Secondly, the method does not do away with the necessity for preliminary mechanical cleansing of the most thorough kind to get rid of all fibrin and other organic matter in trie interstices of the sponge. The expense of the method is slight - a gallon of the persulphate mixture costs less than a shilling.

The marine sponge is so superior in absorbent power to its substitutes that any method which seems likely to insure its sterility should be welcome to surgeons and at least worthy of trial. This is my reason for publishing the foregoing note. Pathological Laboratory, St. Bartholomew's Hospital.

UnIVERstTy of Oxford.-Mr. C. G. Douglas, B.A., Magdalen College, has been elected to a senior scholarship for University students at Guy's Hospital ; Mr. M. W. Flack, B.A., Keble College, to a Price (Universities) scholarship at the London Hospital ; and Mr. J. F. Hornsey, B.A., Wadham College, to a Universities exhibition at Charing Cross Hospital.- Professor Osler will commence his course of instruction introductory to the study of practical medicine on Monday, Oct. 16th. 